\title{
Estrogen receptor gene amplification occurs rarely in ovarian cancer
}

\author{
Rana M Issa ${ }^{1}$, Annette Lebeau ${ }^{1,4}$, Tobias Grob ${ }^{1,4}$, Frederik Holst ${ }^{1,4}$, Holger Moch ${ }^{2}$, \\ Luigi Terracciano ${ }^{3}$, Matthias Choschzick ${ }^{1}$, Guido Sauter ${ }^{1}$ and Ronald Simon ${ }^{1}$ \\ ${ }^{1}$ Department of Pathology, University Medical Center Hamburg Eppendorf, Hamburg, Germany; \\ ${ }^{2}$ Institute of Surgical Pathology, University Hospital Zürich, Zürich, Switzerland and ${ }^{3}$ Department of \\ Pathology, University Hospital Basel, Basel, Switzerland
}

\begin{abstract}
Amplification of the gene encoding estrogen receptor- $\alpha$ occurs in about $20 \%$ of breast cancers and is an important mechanism for estrogen receptor overexpression in this tumor type. In ovarian cancer, overexpression of estrogen receptor protein has been described in more than two thirds of cases. To study a potential role of estrogen receptor- $\alpha$ gene amplification for estrogen receptor overexpression in ovarian cancer, a tumor tissue microarray containing $\mathbf{4 2 8}$ ovarian cancers was analyzed by fluorescence in situ hybridization for estrogen receptor- $\alpha$ gene amplification and immunohistochemistry for estrogen receptor expression. The estrogen receptor- $\alpha$ gene status was successfully determined in 243 of 428 arrayed cancers. Estrogen receptor gene amplification was found in 5 of $243(2 \%)$ of tumors. Amplification levels were usually low, with 4-8 estrogen receptor- $\alpha$ gene copies. However, one case had a high-level amplification, with more than 30 estrogen receptor- $\alpha$ gene copies. All five amplified tumors were estrogen receptor positive, with 3 of 5 tumors showing highest (Allred score, 7-8) estrogen receptor levels. The data demonstrate that estrogen receptor- $\alpha$ amplification occurs only rarely in ovarian cancer.
\end{abstract}

Modern Pathology (2009) 22, 191-196; doi:10.1038/modpathol.2008.130; published online 8 August 2008

Keywords: ovarian cancers; estrogen receptor- $\alpha$ gene; estrogen receptors; fluorescence in situ hybridization; immunohistochemistry

Worldwide, ovarian cancer is the fifth most frequent malignant tumor in women and the most common cause of death among cancers of the reproductive system. ${ }^{1}$ Prognosis is generally poor as these cancers are often detected in late stage. The median overall survival in these patients is $24-38$ months after diagnosis. $^{2}$

Treatment options include surgical removal of the tumor mass with a maximal reduction of the peritoneal cancer mass in case of local tumor extension. In addition, topical and systemic cytotoxic therapy is applied. Ovarian cancer belongs to the group of cancers with frequent expression of steroid hormone receptors. Depending on the study estrogen receptor expression has been reported in $25-86 \%$ of ovarian cancers with the highest percentages reported in endometroid and serous subtypes. ${ }^{3-16}$ Accordingly, endocrine therapy is a

Correspondence: PD Dr R Simon, Institute of Pathology, University Medical Center Hamburg-Eppendorf, Martinistrasse 25, Building N30, Hamburg 20246, Germany.

E-mail: r.simon@uke.uni-hamburg.de

${ }^{4}$ These authors have contributed equally to this study.

Received 16 May 2008; revised and accepted 30 June 2008; published online 8 August 2008 recognized option in the treatment of chemoresistant ovarian cancer after the failure of first- and second-line therapies. However, not all estrogen receptor-positive ovarian cancers respond to antiestrogen therapy, and it was suggested that it might be because of the facts that most of the studies have been retrospective, small in size without adequate selection of the patients and generally used hormonal therapy as a last-line therapy for the refractory or resistant ovarian cancers. Moreover, concerning tamoxifen, it has not been definitely clarified whether it only acts as a pure estrogen antagonist in ovarian tissue, or it has also an agonist effects. ${ }^{17-21}$

In breast cancer, we had recently described estrogen receptor- $\alpha$ (ESR1) gene amplification as a frequent mechanism for estrogen receptor overexpression. More than $20 \%$ of breast cancers showed ESR1 gene amplification and more than $15 \%$ additional cases low-level ESR1 gene copy number gains. ${ }^{22}$ Preliminary data also suggested that ESR1 amplified breast cancers may exhibit a high responsiveness to tamoxifen. To determine, whether ESR1 amplifications also occur in ovarian cancer, we analyzed a set of more than 428 primary ovarian cancers for ESR1 gene amplification. The results of this study suggest that ESR1 amplification is a 
Table 1 Association between histopathological data of ovarian cancers and estrogen receptor protein expression and ESR1 amplification

\begin{tabular}{|c|c|c|c|c|c|c|c|c|c|c|c|}
\hline \multicolumn{9}{|c|}{ Estrogen receptor immunohistochemistry result (ALLRED score) (\%) } & \multicolumn{3}{|c|}{ ESR1 FISH results } \\
\hline & & $\begin{array}{l}\text { On } \\
\text { TMA }\end{array}$ & $\begin{array}{l}\text { Analyzed } \\
\text { (n) }\end{array}$ & $0-2$ & $3-4$ & $5-6$ & $7-8$ & $\mathrm{P}$-value & $\begin{array}{l}\text { Analyzed } \\
\text { (n) }\end{array}$ & $\begin{array}{c}\text { Amplification } \\
(\%)\end{array}$ & $\mathrm{P}$-value \\
\hline \multirow{12}{*}{ Histology } & All cancers & 428 & 384 & 62.8 & 11.2 & 16.7 & 9.4 & & 243 & 2.1 & \\
\hline & $\begin{array}{l}\text { Serous } \\
\text { carcinoma }\end{array}$ & 172 & 158 & 48.7 & 16.5 & 22.8 & 12.0 & $0.0071^{\mathrm{a}}$ & 105 & 1.9 & n.s. ${ }^{a}$ \\
\hline & $\begin{array}{l}\text { Mucinous } \\
\text { carcinoma }\end{array}$ & 76 & 69 & 84.1 & 2.9 & 7.2 & 5.8 & $0.0306^{\mathrm{b}}$ & 40 & 2.5 & n.s. ${ }^{b}$ \\
\hline & Endometroid & 85 & 80 & 55.0 & 13.8 & 21.3 & 10.0 & n.s. ${ }^{\mathrm{c}}$ & 44 & 4.5 & n.s. ${ }^{\mathrm{c}}$ \\
\hline & $\begin{array}{l}\text { Mullerian mixed } \\
\text { cancer }\end{array}$ & 15 & 14 & 100.0 & 0.0 & 0.0 & 0.0 & n.a. & 7 & 0.0 & n.a. \\
\hline & Clear cell cancer & 24 & 24 & 100.0 & 0.0 & 0.0 & 0.0 & n.a. & 13 & 0.0 & n.a. \\
\hline & $\begin{array}{l}\text { Malignant } \\
\text { Brenner tumor }\end{array}$ & 5 & 4 & 50.0 & 0.0 & 50.0 & 0.0 & n.a. & 3 & 0.0 & n.a. \\
\hline & SQCC & 1 & 1 & 100.0 & 0.0 & 0.0 & 0.0 & n.a. & 1 & 0.0 & n.a. \\
\hline & $\begin{array}{l}\text { Sex cord-stromal } \\
\text { tumors }\end{array}$ & 10 & 10 & 60.0 & 10.0 & 0.0 & 30.0 & n.a. & 8 & 0.0 & n.a. \\
\hline & Yolk sack tumor & 4 & 4 & 75.0 & 25.0 & 0.0 & 0.0 & n.a. & 2 & 0.0 & n.a. \\
\hline & $\begin{array}{l}\text { Undifferentiated } \\
\text { carcinoma }\end{array}$ & 15 & 15 & 46.7 & 13.3 & 26.7 & 13.3 & n.a. & 10 & 0.0 & n.a. \\
\hline & Other rare types & 5 & 5 & 100.0 & 0.0 & 0.0 & 0.0 & n.a. & 10 & 0.0 & n.a. \\
\hline \multirow{3}{*}{ pT stage } & pT1 & 58 & 54 & 75.9 & 5.6 & 13.0 & 5.7 & \multirow{3}{*}{0.1343} & 25 & 0.0 & \multirow{3}{*}{ n.s. } \\
\hline & pT2 & 36 & 32 & 78.1 & 6.3 & 6.3 & 9.4 & & 19 & 0.0 & \\
\hline & pT3 & 99 & 88 & 58.0 & 15.9 & 18.2 & 8.0 & & 58 & 1.7 & \\
\hline \multirow{3}{*}{ Silverberg grade } & G1 & 81 & 71 & 71.8 & 5.6 & 14.1 & 8.5 & \multirow{3}{*}{0.038} & 33 & 0.0 & \multirow{3}{*}{ n.s. } \\
\hline & G2 & 91 & 82 & 72.0 & 11.0 & 12.2 & 4.9 & & 52 & 0.0 & \\
\hline & G3 & 91 & 85 & 51.8 & 20.0 & 21.2 & 7.1 & & 55 & 1.8 & \\
\hline
\end{tabular}

${ }^{\mathrm{a}}$ Serous versus mucinous, ${ }^{\mathrm{b}}$ mucinous versus endometroid, ${ }^{\mathrm{c}}$ serous versus endometroid.

SQCC, squamous cell carcinoma.

mechanism for estrogen receptor overexpression only in a very small subset of ovarian cancers.

\section{Materials and methods}

\section{Tissues}

A tumor tissue microarray constructed from primary tumors of 428 ovarian cancer patients was used for this study. The median patient age was 58.1 (range, 24-84) years. Raw survival data were either obtained from the cancer registry of the University of Basel, University Hamburg or collected from the patients attending physicians. The mean follow-up time was 41.85 months (range, 1-210). Formalin-fixed (neutral-buffered aqueous $4 \%$ solution), paraffinembedded tumor material was utilized. The pathologic stage was obtained from the primary pathology reports. All slides from all tumors were reviewed by one pathologist (HM) to define the histological grade and the histological tumor type. The composition of the tumor tissue microarray is described in detail in Table 1.

\section{Fluorescence In Situ Hybridization}

Tumor tissue microarray sections were treated according to the Paraffin Pretreatment Reagent Kit protocol (Vysis, Downers Grove, IL, USA) before hybridization. Fluorescence in situ hybridization (FISH) was performed with a digoxigenated BAC probe (BAC RP11-450E24, RZPD, Germany) containing a part of the ESR1 gene and a Spectrum-Orangelabeled chromosome 6 centromeric probe as a reference (purchased from Vysis). Hybridization and post-hybridization washes were according to the 'LSI procedure' (Vysis). Probe visualization using fluorescent isothiocyanate-conjugated sheep anti-digoxigenin (Roche Diagnostics, Rotkreuz, Switzerland) was as described. ${ }^{23}$ Slides were counterstained with $125 \mathrm{ng} / \mathrm{ml} \mathrm{4}^{\prime}$, 6-diamino-2-phenylindole in an antifade solution. Hybridization and posthybridization washes were according to the 'LSI procedure' (Vysis). Slides were then counterstained

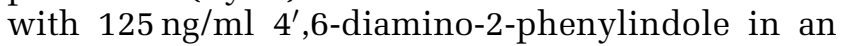
antifade solution. The number of fluorescence signals was estimated by an experienced person (FH) in each tissue spot for the centromere 6 and the ESR1 gene probes. ESR1 alterations were defined based on the ratio of gene copy numbers of ESR1 and centromere 6. Tissues with at least twofold more ESR1 than centromere 6 copies (ratio $\geq 2.0$ ) were considered 'ESR1 amplified'. Tissues with more ESR1 than centromere 6 copies not reaching the criteria for amplification were considered 'ESR1 gained' (ratio $>1.0$ but $<2.0$ ). All other analyzable tissues (ratio 1.0) were considered 'ESR1 normal'. 


\section{Immunohistochemistry}

Immunohistochemical detection of estrogen receptor protein was performed using a monoclonal antibody (DAKO no. M7047, clone 1D5). In brief, $4 \mu \mathrm{m}$ tumor tissue microarray slides were deparaffinized in Xylol prior to heat induced antigen retrieval using DAKO's antigen retrieval solution pH9 (DAKO no. S2368). The primary antibody was diluted 1:50 and incubated for $30 \mathrm{~min}$ at room temperature. The primary antibody was omitted for negative control. All spots were analyzed by one pathologist (RI). Immunohistochemical scoring was performed according to the Allred score. ${ }^{24}$ In brief, estrogen receptor staining intensity was recorded in a 4-step scale (0-3) and the fraction of positive

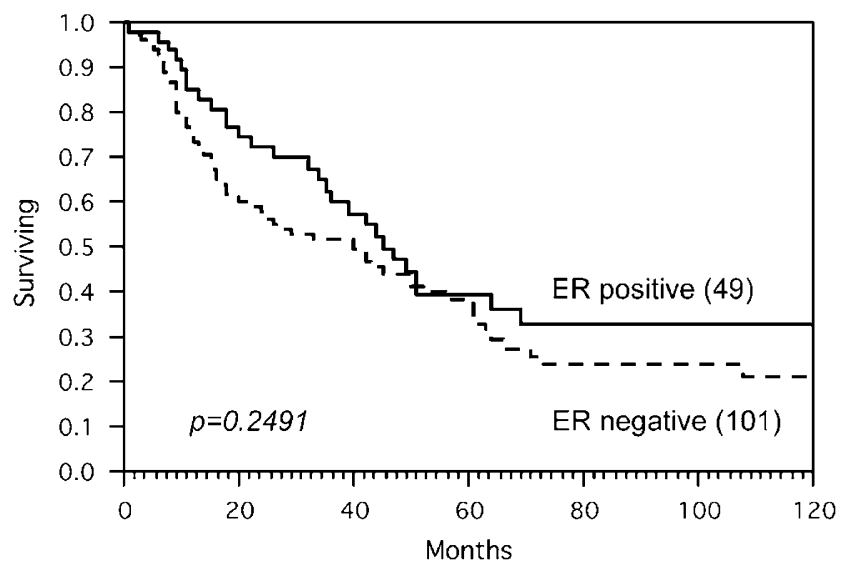

Figure 1 Kaplan-Meier analysis of estrogen receptor (ER) positive and negative ovarian cancers.
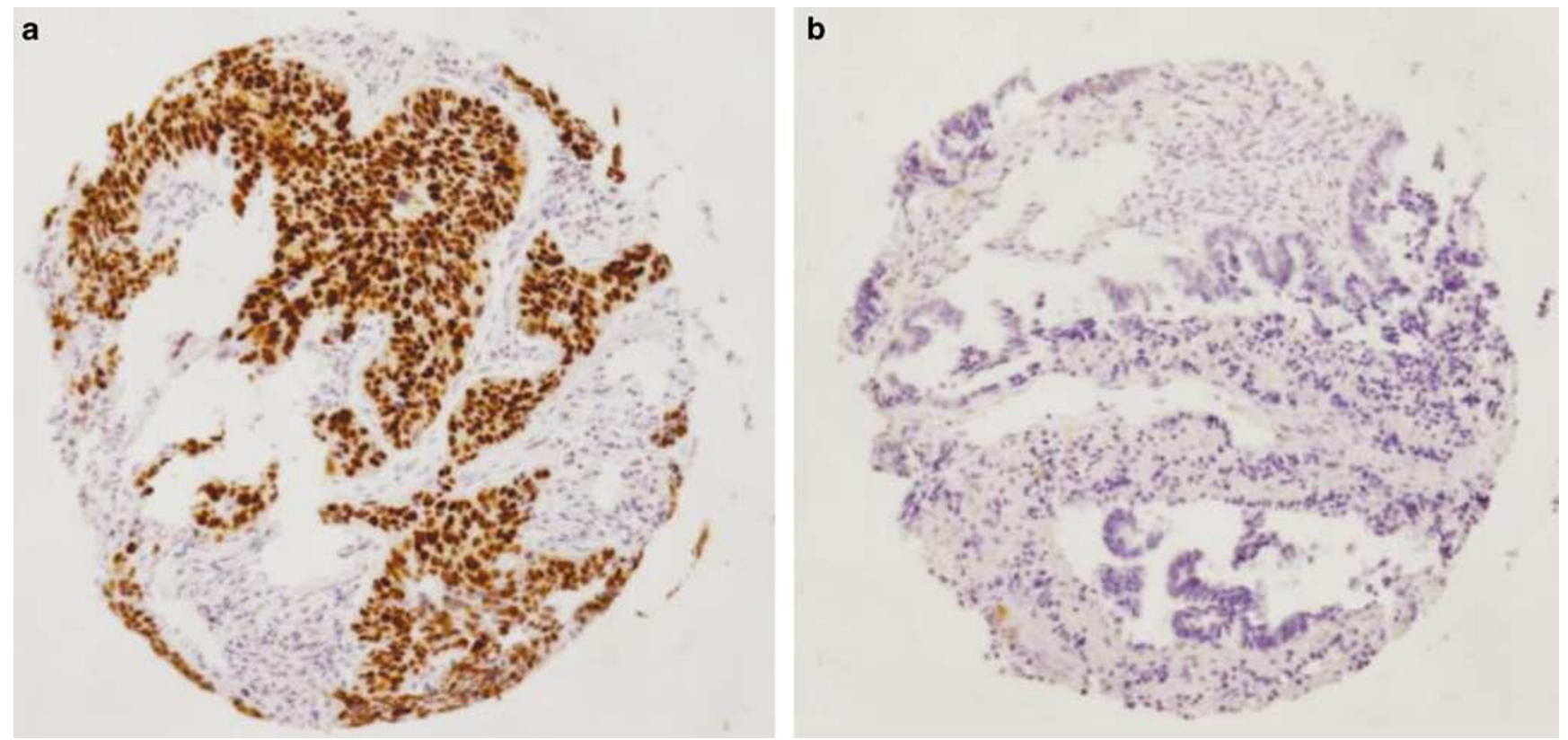

Figure 2 Examples of estrogen receptor positive (a) and negative (b) ovarian cancers. Immunohistochemistry, $\times 100$ magnifications. tumor cells in a 5-step (1-5) scale. Combination of both parameters results in an 8-step score, where all samples with score $>2$ are regarded as estrogen receptor positive.

\section{Statistical Analysis}

Contingency table analysis and $\chi^{2}$-tests were used to study the relationship between clinicopathological parameters of the analyzed tissues and estrogen receptor expression levels. Kaplan-Meier plots and log-rank tests were employed to analyze the relationship between estrogen receptor expression status and patient survival.

\section{Results}

\section{ER Expression}

Immunohistochemical estrogen receptor analysis was successful in 384 of 428 (89, 7\%) arrayed samples. Analysis failure was due to lack of tumor cells in tissue spots $(n=19,4.4 \%)$ or missing tissue spots $(n=24,5.6 \%)$. More than one-third (148 of $384,37.2 \%)$ of tumors showed at least weak estrogen receptor expression. Strongest staining (score 7-8 according to Allred) was found in 36 of 384 (9.4\%) of samples, and was linked to high-grade cancers $(P=0.038)$. Estrogen receptor expression was unExamples of immunohistochemically positive and negative tumors are shown in Figure 2. All immunohistochemistry results are summarized in Table 1. related to patient prognosis $(P=0.2491$, Figure 1$)$. 

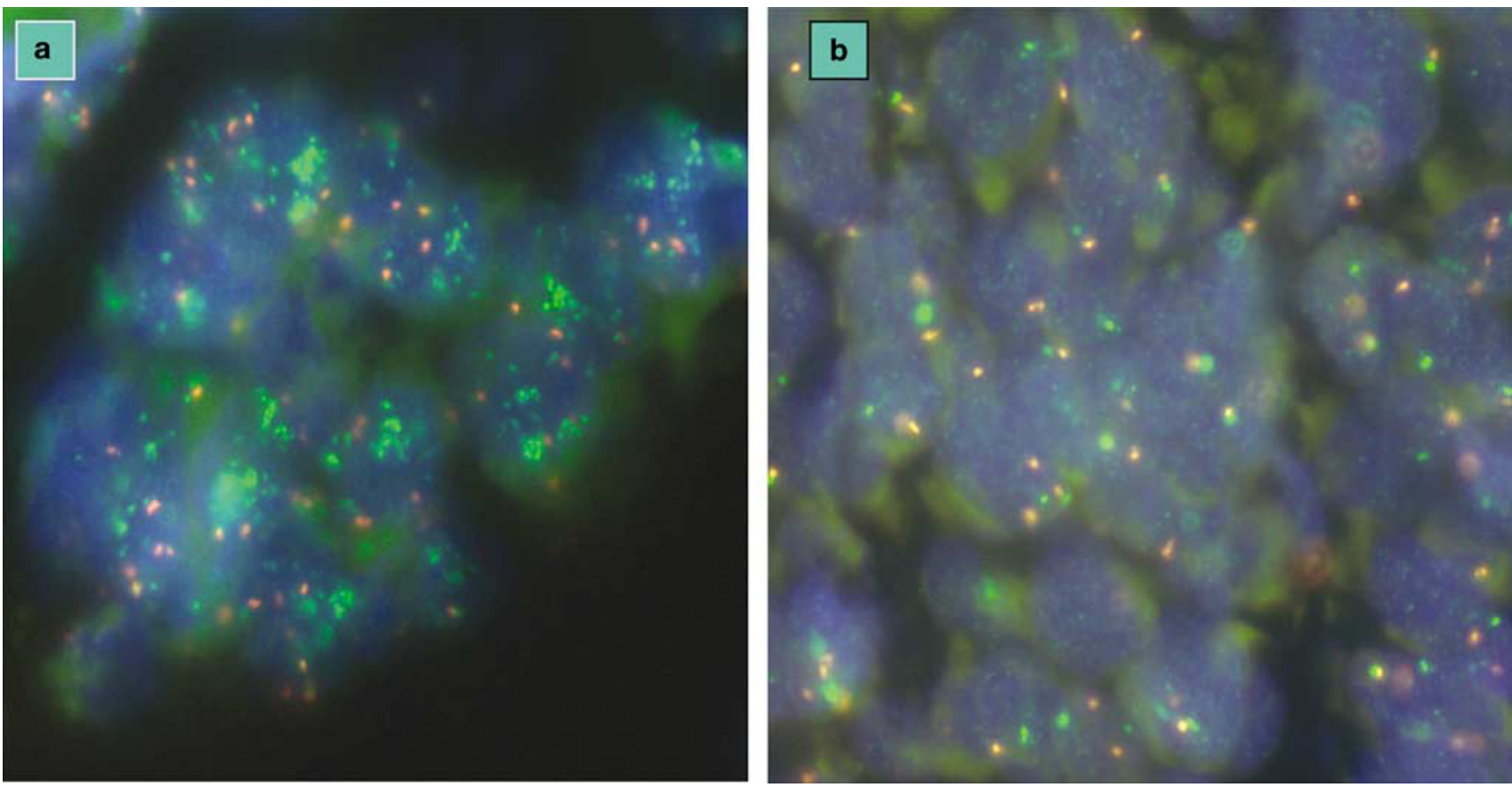

Figure 3 Examples of ovarian cancers with ESR1 amplification (a) and with normal ESR1 copy numbers (b). Red signals indicate copy number of centromere 6; green signals indicate ESR1 copy numbers. FISH analysis, $\times 630$ magnifications.

\section{ESR1 Amplification}

ESR1 FISH analysis was successful in 243 of 428 arrayed tissue samples. Missing results were either due to missing tissue samples on the tumor tissue microarray $(n=80)$ or lack of interpretable FISH signals $(n=105)$. ESR1 amplification (ratio ESR1) centromere $6 \geq 2.0$ ) was found in 5 of $243(2.1 \%)$ tumors. Amplifications were usually low level with 4-8 FISH signals. One sample had a highlevel amplification ( $>10$ signals; Figure 3$)$. Examples of ESR1 amplified and non-amplified tumors are shown in Figure 3. ESR1 amplification was unrelated to histopathological parameters including histological subtype, tumor stage, and grade. No survival analysis was performed because of the small number of cases with ESR1 amplification.

All five tumors with ESR1 amplification were variably positive for estrogen receptors protein expression with strong positivity in three out of five cases.

\section{Discussion}

The results of this study show that ESR1 amplification is rare in ovarian cancers $(2.1 \%)$. More than one-third of ovarian tumors showed immunohistochemically detectable estrogen receptor protein expression, most abundant in serous and endometroid subtypes. This is in line with previous studies done on the classical paraffin blocks. The good concordance between our data and previous studies demonstrates the representation of our tumor tissue microarray data obtained on a $0.6 \mathrm{~mm}$ tissue spot per tumor and enhances the results of other studies used in this method.

A small subset of ESR1 amplified estrogen receptorpositive cases was indeed found in ovarian cancers. In comparison, some other genes showed higher rates of amplifications in these cancers. For example, the amplification of ERBB2 ranges (0-66\%), ${ }^{25,26}$ EGFR (3.65-12\%), ${ }^{27,28} C C N D 1$ (0-19\%), ${ }^{29-31} C-M Y C$ up to $54.5,{ }^{25,32,33}$ and KRAS $(31 \%) .{ }^{33}$

The significant frequency of estrogen receptor positivity in ovarian cancers had prompted treatment efforts using hormonal therapy early on. In addition their relatively little toxicity was another provoking factor to continue going on to achieve more advance in this therapeutic field. Monotherapy studies using tamoxifen, aromatase inhibitors, and $\mathrm{GnRH}$ analogues had yielded variable results with objective response rates ranging between 0 and $56 \% .^{17,19-21,34-38}$ Combinatorial treatment regimens combining tamoxifen and goserelin or tamoxifen and Gefitinib had obtained results with objective response rates of up to $11.5 \% .^{39,40}$ Few of these studies had selected patients based on the immunohistochemically determined estrogen receptor status. It is therefore unclear, whether the estrogen receptor expression level has any impact on the likelihood of response, or this just reflects the lack of establishment of well-organized treatment strategy in previously heavily treated patients and who in significant part already suffered from advanced disease. 
The role of estrogen receptor expression for response prediction to anti-hormonal drugs has been much better studied in breast cancer, where a strong association between estrogen receptor positivity and response to anti-hormonal drugs is well established. However, also in breast cancer, not all estrogen receptor-positive cancers respond to tamoxifen and related drugs. In a recent study, we had found that ESR1 amplification may be strongly predict tamoxifen response among estrogen receptor-positive breast cancers. More than $20 \%$ of breast cancers had amplified or at least elevated ESR1 copy number. Possible explanations for the predictive effect of ESR1 amplification could be a particularly high expression of amplified as compared to non-amplified cancers. Alternatively, it could be speculated, that ESR1 amplified are more dependent on the estrogen receptor pathway than other tumors that express estrogen receptors together with many other growth receptors. If this latter hypothesis was true, visualization of ESR1 amplification would pinpoint toward an 'Achilles tendon' of a tumor that could be most successfully targeted.

The frequency of ESR1 amplified ovarian cancers $(2.1 \%)$ is much lower than that in breast cancer. Interestingly, this fraction somehow parallels the percentage of ovarian cancers reported to show strong responses to hormonal therapies. For example, in retrospective, analysis was conducted of patients who received tamoxifen at a dose $20 \mathrm{mg}$ twice daily for the treatment of advanced epithelial ovarian cancer, Karagol et $a l^{41}$ found that out of 29 eligible patients included in the study, there were $1(3 \%)$ complete response, 2 (7\%) partial response, $6(21 \%)$ stable disease, and $20(69 \%)$ progressive disease. Papadimitriou et $a l^{35}$ have studied response rate in 27 patients treated with letrozole at a dose of $2.5 \mathrm{mg}$ once a day. Patients with measurable or evaluable disease $(n=21)$ and those with only increasing CA-125 serum levels $(n=6)$ were eligible. Among the 21 patients with measurable or evaluable disease, 1 complete response $(5 \%)$ and 2 partial responses were observed $(10 \%)$ for an objective response rate of $15 \%$. Other studies, in which the combined regiment had been implicated, patients were given oral tamoxifen $20 \mathrm{mg}$ twice daily on a continuous basis and subcutaneous goserelin $3.6 \mathrm{mg}$ once a month until disease progression. In total, 26 patients entered this study, of which 17 had platinumresistant disease, using the definition of endocrine response that included patients with stable disease of 6 months or greater, the overall response rate (clinical benefit rate) was $50 \%$. This included one complete response $(3.8 \%)$, two partial responses $(7.7 \%)$, and 10 patients with stable disease $(38.5 \%){ }^{39}$

In summary, ESR1 amplification is an uncommon mechanism for estrogen receptor overexpression in ovarian cancer occurring in about $2.1 \%$ of the total number of ovarian cancers. In general, this frequency parallels the fraction of ovarian cancers reported to show complete response to antiestrogenic therapies. Given the strong predictive power of ESR1 amplification for response to tamoxifen in breast cancer, an evaluation of such treatments in ESR1 amplified ovarian cancers appears justified.

\section{Acknowledgements}

We are grateful to Ms Michaela Härtling, Ms Sandra Schmidt, Ms Silvia Schnöger, and Mr Sascha Eghtessadi for excellent technical assistance in immunohistochemistry and FISH analysis, and to Ms Martina Mirlacher for tumor tissue microarray making.

\section{References}

1 Kurman RJ, (ed). Blaustein's Pathology of the Female Genital Tract. 5th edn. Springer: New York, 2002, 791p.

2 Smyth JF, Gourley C, Walker G, et al. Antiestrogen therapy is active in selected ovarian cancer cases: the use of letrozole in estrogen receptor-positive patients. Clin Cancer Res 2007;13:3617-3622.

3 Vang R, Whitaker BP, Farhood AI, et al. Immunohistochemical analysis of clear cell carcinoma of the gynecologic tract. Int J Gynecol Pathol 2001;20: 252-259.

4 Teufel G, Geyer H, de Gregorio G, et al. Estrogen and progesterone receptors in malignant ovarian neoplasms. Geburtshilfe Frauenheilkd 1983;43:732-740.

5 De Sousa Damião R, Fujiyama Oshima CT, Stávale JN, et al. Analysis of the expression of estrogen receptor, progesterone receptor and chicken ovalbumin upstream promoter-transcription factor I in ovarian epithelial cancers and normal ovaries. Oncol Rep 2007;18:25-32.

6 Kommoss F, Pfisterer J, Thome M, et al. Steroid receptors in ovarian carcinoma: immunohistochemical determination may lead to new aspects. Gynecol Oncol 1992;47:317-322.

7 Rosen DG, Huang X, Deavers MT, et al. Validation of tissue microarray technology in ovarian carcinoma. Mod Pathol 2004;17:790-797.

8 Vang R, Gown AM, Barry TS, et al. Immunohistochemistry for estrogen and progesterone receptors in the distinction of primary and metastatic mucinous tumors in the ovary: an analysis of 124 cases. Mod Pathol 2006;19:97-105.

9 Van Doorn HC, Burger CW, van der Valk P, et al. Oestrogen, progesterone, and androgen receptors in ovarian neoplasia: correlation between immunohistochemical and biochemical receptor analyses. J Clin Pathol 2000;53:201-205.

10 Lindgren PR, Cajander S, Bäckström T, et al. Estrogen and progesterone receptors in ovarian epithelial tumors. Mol Cell Endocrinol 2004;221:97-104.

11 Lindgren P, Backstrom T, Mahlck CG, et al. Steroid receptors and hormones in relation to cell proliferation 
and apoptosis in poorly differentiated epithelial ovarian tumors. Int J Oncol 2001;19:31-38.

12 Van Mieghem T, Abeler VM, Moerman P, et al. CD10, estrogen and progesterone receptor expression in ovarian adenosarcoma. Gynecol Oncol 2005;99:493-496.

13 Cardillo MR, Petrangeli E, Aliotta N, et al. Androgen receptors in ovarian tumors: correlation with oestrogen and progesterone receptors in an immunohistochemical and semiquantitative image analysis study. J Exp Clin Cancer Res 1998;17:231-237.

14 Farinola MA, Gown AM, Judson K, et al. Estrogen receptor alpha and progesterone receptor expression in ovarian adult granulosa cell tumors and Sertoli-Leydig cell tumors. Int J Gynecol Pathol 2007;26:375-382.

15 Ho SM. Estrogen, progesterone and epithelial ovarian cancer. Reprod Biol Endocrinol 2003;1:73.

16 Høgdall EV, Christensen L, Høgdall CK, et al. Prognostic value of estrogen receptor and progesterone receptor tumor expression in Danish ovarian cancer patients: from the 'MALOVA' ovarian cancer study. Oncol Rep 2007;18:1051-1059.

17 Perez-Gracia JL, Carrasco EM. Tamoxifen therapy for ovarian cancer in the adjuvant and advanced settings: systematic review of the literature and implications for future research. Gynecol Oncol 2002;84:201-209.

18 Langdon SP, Crew AJ, Ritchie AA, et al. Growth inhibition of oestrogen receptor-positive human ovarian carcinoma by anti-oestrogens in vitro and in a xenograft model. Eur J Cancer 1994;30A:682-686.

19 Makar AP. Hormone therapy in epithelial ovarian cancer. Endocr Relat Cancer 2000;7:85-93.

20 Clinton GM, Hua W. Estrogen action in human ovarian cancer. Crit Rev Oncol Hematol 1997;25:1-9.

21 Cunat S, Hoffmann P, Pujol P. Estrogens and epithelial ovarian cancer. Gynecol Oncol 2004;94:25-32.

22 Holst F, Stahl PR, Ruiz C, et al. Estrogen receptor alpha (ESR1) gene amplification is frequent in breast cancer. Nat Genet 2007;39:655-660.

23 Wagner U, Bubendorf L, Gasser TC, et al. Chromosome $8 \mathrm{p}$ deletions are associated with invasive tumor growth in urinary bladder cancer. Am J Pathol 1997;151:753-759.

24 Harvey JM, Clark GM, Osborne CK, et al. Estrogen receptor status by immunohistochemistry is superior to the ligand-binding assay for predicting response to adjuvant endocrine therapy in breast cancer. J Clin Oncol 1999;17:1474-1481.

$25 \mathrm{Wu}$ R, Lin L, Beer DG, et al. Amplification and overexpression of the L-MYC proto-oncogene in ovarian carcinomas. Am J Pathol 2003;162:1603-1610.

26 Leary JA, Edwards BG, Houghton CR, et al. Amplification of HER-2/neu oncogene in human ovarian cancer. Int J Gynecol Cancer 1992;2:291-294.

27 Lassus H, Sihto H, Leminen A, et al. Gene amplification, mutation, and protein expression of EGFR and mutations of ERBB2 in serous ovarian carcinoma. J Mol Med 2006;84:671-681.

28 Dimova I, Raitcheva S, Dimitrov R, et al. Correlations between c-myc gene copy-number and clinicopathological parameters of ovarian tumours. Eur J Cancer 2006;42:674-679.

29 Masciullo V, Scambia G, Marone M, et al. Altered expression of cyclin D1 and CDK4 genes in ovarian carcinomas. Int J Cancer 1997;74:390-395.

30 Courjal F, Louason G, Speiser P, et al. Cyclin gene amplification and overexpression in breast and ovarian cancers: evidence for the selection of cyclin D1 in breast and cyclin $\mathrm{E}$ in ovarian tumors. Int J Cancer 1996;69:247-253.

31 Diebold J, Mösinger K, Peiro G, et al. 20q13 and cyclin D1 in ovarian carcinomas. Analysis by fluorescence in situ hybridization. J Pathol 2000;190:564-571.

32 Xin XY. The amplification of c-myc, N-ras, c-erb B oncogenes in ovarian malignancies. Zhonghua $\mathrm{Fu}$ Chan Ke Za Zhi 1993;28:405-407, 42.

33 Bian M, Fan Q, Huang S. Amplification of proto-oncogenes C-myc, C-N-ras, C-Ki-ras, C-erbB2 in ovarian carcinoma. Zhonghua $\mathrm{Fu}$ Chan Ke Za Zhi 1995;30:406-409.

$34 \mathrm{Li} \mathrm{YF}, \mathrm{Hu} \mathrm{W}, \mathrm{Fu} \mathrm{SQ}$, et al. Aromatase inhibitors in ovarian cancer: is there a role?. Int J Gynecol Cancer 2007; doi:10.1111/j.1525-1438.2007.01075.x, e-pub ahead of print.

35 Papadimitriou CA, Markaki S, Siapkaras J, et al. Hormonal therapy with letrozole for relapsed epithelial ovarian cancer. Long-term results of a phase II study. Oncology 2004;66:112-117.

36 Balbi G, Piano LD, Cardone A, et al. Second-line therapy of advanced ovarian cancer with GnRH analogs. Int J Gynecol Cancer 2004;14:799-803.

37 Trope C, Marth C, Kaern J. Tamoxifen in the treatment of recurrent ovarian carcinoma. Eur J Cancer 2000; 36(Suppl 4):S59-S61.

38 Levine D, Park K, Juretzka M, et al. Phase II evaluation of goserelin and bicalutamide in patients with ovarian cancer in second or higher complete clinical disease remission. Cancer 2007;110:2448-2456.

39 Hasan J, Ton N, Mullamitha S, et al. Phase II trial of tamoxifen and goserelin in recurrent epithelial ovarian cancer. Br J Cancer 2005;93:647-651.

40 Wagner $\mathrm{U}$, du Bois A, Pfisterer J, et al. AGO Ovarian Cancer Study Group: Gefitinib in combination with tamoxifen in patients with ovarian cancer refractory or resistant to platinum-taxane based therapy - a phase II trial of the AGO Ovarian Cancer Study Group (AGO-OVAR 2.6). Gynecol Oncol 2007;105: 132-137.

41 Karagol H, Saip P, Uygun K, et al. The efficacy of tamoxifen in patients with advanced epithelial ovarian cancer. Med Oncol 2007;24:39-43. 